\title{
What Makes Voters Turn Out: The Effects of Polls and Beliefs
}

\author{
Marina Agranov* Jacob K. Goeree ${ }^{\dagger} \quad$ Julian Romero ${ }^{\ddagger}$ \\ Leeat Yariv $^{\S \Phi}$
}

December 29, 2014

\begin{abstract}
We use laboratory experiments to test for one of the foundations of the rational voter paradigm - that voters respond to probabilities of being pivotal. We exploit a setup that entails stark theoretical effects of information concerning the preference distribution (as revealed through polls) on costly participation decisions. We find that voting propensity increases systematically with subjects' predictions of their preferred alternative's advantage. Consequently, pre-election polls do not exhibit the detrimental welfare effects that extant theoretical work predicts. They lead to more participation by the expected majority and generate more landslide elections.
\end{abstract}

JEL classification: C92, D02, D72

Keywords: Collective Choice, Polls, Strategic Voting.

${ }^{*}$ Division of the Humanities and Social Sciences, Caltech. E-mail: magranov@hss.caltech.edu

$\dagger$ University of Sydney and University of Cologne. E-mail: Jacob.Goeree@uts.edu.au

$¥$ Department of Economics, Purdue University. E-mail: jnromero@purdue.edu

$\S$ Division of the Humanities and Social Sciences, Caltech. E-mail: lyariv@hss.caltech.edu

"We thank Guillaume Frechette, Salvatore Nunnari, and Tom Palfrey for useful suggestions. We gratefully acknowledge financial support from the European Research Council (ERC Advanced Investigator Grant, ESEI-249433), the National Science Foundation (SES 0963583), and the Henry and Betty Moore Foundation. 


\section{Introduction}

\subsection{Overview}

At the core of the pivotal voter model is the idea that voters respond to the likelihood that their vote will matter for the collective decision, i.e., that they will be pivotal. This canonical model has many important implications. If participation is at all costly (be it due to travel costs involved in getting to the booth for political voters, time costs for

faculty invited to a recruiting meeting, etc.), greater turnout is to be expected when the likelihood of a close decision is higher. Furthermore, information regarding the distribution of preferences, such as the fraction of the population that supports one alternative relative to another, would induce those in the minority to participate at greater rates. Consequently, any such information, which is commonly distributed through polls, would have detrimental welfare effects. It would induce more costly participation and make the majority-preferred alternative less likely to be selected.

Large political elections provide a rather challenging case for the underlying premise of the pivotal voter model. Indeed, probabilities of pivotality are perceived to be pervasively low - for example, Mulligan and Hunter (2003) estimate that approximately one of every 100,000 votes cast in U.S. Congressional elections, and one of every 15,000 votes cast in state legislator elections, 'mattered' in that they were cast for a candidate that tied or won the election by precisely one vote. Nonetheless, the value of participation in political elections is hard to assess, and the pivotal voter model could still provide useful guidance in terms of the effects of information on outcomes, the behavior of individuals in small groups making collective decisions in which pivot probabilities are substantial, etc.

Previous experimental work has suggested that higher probabilities of pivotality indeed induce greater participation rates (see literature review below for an elaborate discussion), in support of the pivotal voter model. Nonetheless, elections that are not close can be of two sorts from the perspective of a voter. They can correspond to the voter's preferred candidate either winning or losing by a large margin. The pivotal voter model prescribes that, conditional on the election not being close, which of these two consequences the voter believes in should not matter for the comparative statics regarding participation - 
she should still participate less than when elections are predicted to be close. One of the goals of the current paper is to unpack the two types of landslide elections and re-examine the pivotal voter model. In addition, we study mechanisms by which voters form beliefs regarding election outcomes, namely election polls.

Specifically, the paper describes an array of experiments that focus on the explicit link between voters' beliefs and their participation decisions. These are some of the first experiments to elicit beliefs directly in a variety of informational settings. ${ }^{1}$ In particular, we consider the impact of information revealed through polls and the welfare consequences they entail. Our design therefore contributes to the understanding of how individuals report their intentions in polls as well.

In detail, 22 groups of 9 subjects each participated in a total of 440 elections between two alternatives. Subjects had to choose one of two colors: Red or Blue, using majority rule. At the outset of each election, one of two jars was selected at random - a "red" or a "blue" jar. The red jar contained two red balls and one blue ball and the blue jar contained two blue balls and one red ball. Each of the nine subjects in a group received an independent draw (with replacement) from the selected jar. The color of the drawn ball represented the subject's preferred alternative (and, therefore, the chosen jar captured the distribution of preferences). Ultimately, each subject had to decide whether to cast a costly vote for either Red or Blue, or whether to abstain.

We considered three treatments. In all treatments subjects knew their own preferred color. In our baseline No Polls treatment, subjects were provided with no further information. In the Perfect Polls treatment, subjects were also informed of the selected jar. In particular, subjects knew the alternative likely to be supported by a majority. In the Lab Polls treatment, subjects participated in a poll reporting their voting intentions and were told the results of that poll before deciding whether to cast a vote or abstain. In all groups, subjects were asked to predict the group preference composition and ultimate voting profile prior to voting, i.e. report their beliefs regarding the outcome of the election.

The experimental data reveal several interesting insights. First, with regards to the pivotal voter model, turnout rates are significantly higher for elections that are predicted

\footnotetext{
${ }^{1}$ See the literature review below for exceptions.
} 
to be close relative to all others aggregated together, as noted in previous papers (see below). However, the pivotal voter model has far richer predictions, it predicts essentially a hump-shaped response to expected leads - when either alternative is expected to have a large lead, participation should be low. To our knowledge, our paper is the first to allow for a more refined look into the response of turnout to beliefs. In particular, we can unpack responses to expected landslide victory and expected landslide loss of one's preferred alternative. Our data reveals a monotonic pattern that is not in line with the pivotal voter model - while subjects participated at lower rates when expecting a great loss of their preferred color, the more likely subjects thought their preferred color was to win, the more likely they were to vote. In particular, subjects voted at substantial rates even when expecting a landslide victory of their preferred alternative. Our design allows us to rule out this fundamental violation of the pivotal voter model as emerging from risk aversion, loss aversion, regret, or ethical voting. However, a modification of the pivotal voter model a-la Callander (2007) in which voters receive a benefit from voting for the winner of an election explains a large fraction of our data.

Second, the information regarding the preference distribution in the population does not have a detrimental effect on welfare as theory would predict. In fact, all of our treatments yield comparable welfare levels. From a policy perspective, this suggests that dispelling information in the electorate would not be as harmful as our standard theoretical framework would suggest. Furthermore, while the pivotal voter model would imply that polls, indictating which alternative is supported by a majority of the population, would induce minority supporters to turn out more and therefore lead to closer elections, in our experiments landslide elections are significantly more common when more information is available to the electorate.

Last, our design allows us to inspect the behavior of subjects in polls. In our experimental polls, very few subjects misreport the alternative they will vote for. However, there is substantial discrepancy between declared intentions to participate and ultimate turnout decisions. Pre-election polls consistently overestimate voter turnout. ${ }^{2}$ In our ex-

\footnotetext{
${ }^{2}$ This phenomenon has been diagnosed in a variety of polling environments. For instance, the American National Election Study (ANES) is prone to exaggerated reported intentions to turn out (see Holbrook and Krosnick, 2010 and references therein).
} 
periments, $82 \%$ of subjects reported that they will vote, while in fact no more than $50 \%$ actually voted (and, of those reporting they will vote, only $42 \%$ ultimately participated). The patterns of ultimate participation shed light on some of the empirical observations regarding polls. There is a large body of literature pioneered by Simon (1954), Fleitas (1971), and Gartner (1976) suggesting that polls may lead to Bandwagon Effects, making poll winners win with even greater leads than predicted, or Underdog Effects, leading poll winners to lose votes in the actual election. The empirical literature has been inconclusive regarding which of these two effects is expected to dominate in different environments. Our results illustrate that which effect prevails depends on the margins of victory elicited by the polls. When poll victories are small, Bandwagon Effects appear, while when polls predict a landslide victory for one of the alternatives, Underdog Effects are observed.

While we use the terminology of political elections, thinking of subjects as voters, there are certainly many motives that could affect participation in large political elections that are not tied to pivotality (civic duty, social pressure, etc.). Our experiments illustrate that even absent these additional motives, participation can be substantial when the pivotal voter model would predict otherwise. Furthermore, our experimental setup can be thought of as a metaphor for a wide variety of settings in which small groups make collective decisions, including investment decisions by corporate strategy committees, hiring and promotion decisions by university faculty, and so on.

\section{$1.2 \quad$ Related Literature}

The crux of the pivotal voter model is the observation that a vote matters only when it is pivotal. When preferences are private, the pivotal voter model translates into a simple cost-benefit analysis. A voter needs to contemplate the probability that her vote determines the election (the benefit) and weigh it against the cost of participation. Suppose two alternatives are being considered. In a model in which all voters experience the same distribution of participation costs, as in Palfrey and Rosenthal (1983) and Borgers (2004), majority supporters will participate less than minority supporters, and overall 
participation will decline with participation costs. ${ }^{3}$

Some of the theoretical predictions of the pivotal voter model have been observed in the lab. Levine and Palfrey (2007) directly tested the Palfrey and Rosenthal (1983) model and found confirmation for the main comparative statics predicted by the model. For example, Levine and Palfrey document that participation declines with participation costs. This result has also been documented by Cason and Mui (2005) and Kartal (2014) in slightly different settings. Nonetheless, most experimental studies find that majority supporters vote with greater propensities than minority ones (see Duffy and Tavits, 2008, Großer and Schram, 2010, and Kartal, 2014), contrasting the predictions of the pivotal voter model. ${ }^{4}$

When the distribution of preferences is commonly known, the most efficient outcome (corresponding to the majority-preferred alternative when payoffs are symmetric) can be deduced absent an election. The recent literature has therefore suggested that it is uncertainty over preferences in the electorate that make elections an important collective decision instrument. Goeree and Großer (2007) and Taylor and Yildrim (2010) consider models in which there is uncertainty over who is the majority-preferred candidate. Absent any information, individuals cannot condition their participation on whether or not they are majority supporters. Participation rates are therefore comparable across the minority and majority camps and the majority-preferred candidate is likely to be chosen. Polls, however, provide information to voters regarding their likelihood of belonging to the majority. Information regarding the distribution of preferences may induce minority supporters to vote more since their likelihood to affect election outcomes is higher. Therefore, polls may lead to more participation, and lower likelihood of the majority-preferred candidate to be selected. These papers then conclude that polls have a negative welfare effect. ${ }^{5}$

\footnotetext{
${ }^{3}$ When there is uncertainty over which alternative is superior, a strategic agent also considers the information contained in the event of being pivotal, taking into account others' strategies (see AustenSmith and Banks, 1996; Myerson, 1998; Feddersen and Pesendorfer, 1996, 1997, 1998).

${ }^{4}$ The only experimental paper reporting greater minority support is Levine and Palfrey (2007). However, the differences in observed participation rates in this setup are rather small: when the size of the electorate is 9, majority supporters vote at a rate of $40 \%$ or $45 \%$, while minority supporters vote at a rate of $44 \%$ or $48 \%$, depending on the relative volume of minority supporters.

${ }^{5}$ The effects of polls in information aggregation settings is analyzed in Coughlan (2000). The effects of free-form communication preceding elections, with either private information or private preferences,
} 
Several papers have considered the impact of information on preferences in the lab. Duffy and Tavits (2008) observe a positive association between predicted closeness of an election and participation rates. Nonetheless, they do not observe subjects' beliefs regarding ultimate outcomes and therefore cannot distinguish between landslide elections that culminate in a victory or a loss for the preferred candidate.

Großer and Schram (2010) and Klor and Winter (2007) consider experimental polls that reveal the precise distribution of preferences in the electorate (effectively mimicking the Palfrey and Rosenthal, 1983, setting). They find that polls by and large increase turnout and have welfare effects that depend on how equally divided support is. ${ }^{6}$ When there are unequal levels of support, polls have non-negative welfare effects. However, in closely divided electorates, polls have detrimental effects on welfare. ${ }^{7,8}$

As a summary, we note that the experiments described in this paper provide three important methodological innovations. First, we elicit subjects' beliefs regarding election outcomes prior to their choices, information that is especially challenging to gather from field data. This allows us to test the pivotal voter model in a direct manner. In particular, we can unfold the responses to different events corresponding to elections that are not close - those in which the preferred alternative is predicted to win with a landslide, and those in which the opposing candidate is predicted to win with a large victory margin. Second, we study organic responses to polls run in the lab and can therefore inspect both the behavior in the polls themselves as well as individual responses to poll results. ${ }^{9}$ appears in Gerardi and Yariv (2007).

${ }^{6}$ In particular, both papers document that knowing that one belongs to the majority group increases participation probabilities.

${ }^{7}$ Forsythe, Myerson, Rietz, and Weber (1993) consider polls in elections with complete information involving more than two candidates. There is also an experimental literature considering different forms of communication preceding elections in which participation is free, but individuals have private information regarding the 'quality' of either of the two candidates; See Goeree and Yariv (2011), Guarnaschelli, McKelvey, and Palfrey (2000), and references therein. Sinclair and Plott (2012) consider experimental spatial elections in which candidates' locations are uncertain and observe how polls allow subjects to ultimately behave as if they are informed.

${ }^{8}$ For a general review of political economy experiments, see Palfrey (2006). There is also some empirical work investigating the predictions of the pivotal voter model regarding turnout in small-scale elections. Coate and Conlin (2004) and Coate, Conlin, and Moro (2008) use data from the Texas liquor referenda and illustrate the limited guidance the pivotal voter model provides in predicting outcomes.

${ }^{9}$ There exists a large empirical literature in Political Science that investigates how polls influence voters' behavior. One of the problematic aspects of most of the field studies on this topic is the necessity to disentangle whether polls affect preferences, or change voters' propensity to vote. Our experiments 
Last, all of our settings entail some uncertainty over which alternative is favored by the majority, environments in which collective decision protocols and institutions matter the most. After all, if the majority-preferred candidate were known in advance, there would be no need to hold an election.

\subsection{Paper Structure}

Section 2 describes the experimental design. The corresponding theoretical predictions are analyzed in Section 3. We present the experimental results in Sections 4-6 in the following order. We start by inspecting individual voting behavior in elections and how it responds to beliefs regarding the lead of the preferred alternative (Section 4). We then move to inspecting the effects of the observed behavior on outcomes in Section 5 . We first look at the emergent lead of elections, and then study the effects of polls on both leads and welfare. Finally, in Section 6 we analyze reports in the experimental polls and their effects on ultimate outcomes. Section 7 concludes.

\section{Experimental Design}

We use a sequence of experiments to assess voters' response to information and beliefs regarding the underlying distribution of preferences. 10 There is a "red" jar and a "blue" jar: the red jar contains two red balls and one blue ball and the blue jar contains two blue balls and one red ball. We use the color of the jar as a metaphor for the inclination of the decision-making group (a committee, an electorate) toward one of two alternatives that are being considered (an investment opportunity, a political candidate). At the start of each session, subjects are randomized into a group of nine subjects. ${ }^{11}$ The timing of each of our sessions was as follows:

provide a clean separation between these two channels, since voter preferences are fixed.

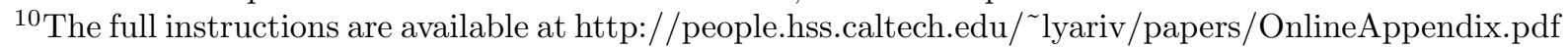

${ }^{11}$ We kept subjects in the same group throughout each session in order to avoid potential 'contamination' across groups and since repeated game effects seemed particularly difficult in this setting. In fact, subjects did not seem to exhibit any group-dependent inter-temporal correlation in behavior (see Section $4.3)$. 
States and Preferences. At the start of each of 20 periods, one of the jars is chosen by a toss of a fair coin. In each period, after the jar had been selected, each of the nine subjects in a group receives an independent draw (with replacement) from the selected jar. The color of the drawn ball matches the jar's color with probability $p=2 / 3$. Ultimately, each group of subjects chooses an alternative - red or blue. The individual color each subject draws corresponds to the subject's preferred alternative.

Polls. Depending on the treatment, subjects were provided some information on the realized jar. Specifically, we had three types of sessions:

No Polls Subjects know that each jar had a $50-50$ probability of being selected, but observe no information on the realized jar other than their private draw.

Perfect Polls Subjects are perfectly informed of the realized jar in each period. This corresponds to a situation in which agents' preferences are polled perfectly so that the distribution of preferences in the population is transparent to all. ${ }^{12}$

$\boldsymbol{L} \boldsymbol{a b}$ Polls After private draws (i.e., preferences) for a period are revealed, subjects are asked to declare their intended actions: abstain, vote for red, or vote for blue. The resulting overall statistics (number of subjects intending to abstain, vote for red, and vote for blue) are then reported to subjects. This treatment replicates real polls in which subjects may potentially be strategic when responding to the polls and not necessarily report their actual intended actions. ${ }^{13}$

Beliefs. After receiving information regarding the realized jar as determined by one of the three treatments, subjects are asked to report their beliefs regarding the composition of the group (number of subjects preferring red and number of subjects preferring blue), as well as the distribution of votes (for red and blue). ${ }^{14}$ At the end of the experiment,

\footnotetext{
${ }^{12}$ For example, if the color of the realized jar was blue, then each subject knows that each member of the group has a $2 / 3$ chance of drawing a blue ball and a $1 / 3$ chance of drawing a red ball.

${ }^{13}$ Our lab polls setting is similar to that studied theoretically by Morgan and Stocken (2008) in the context of information aggregation.

${ }^{14}$ Subjects' guesses regarding group composition had to specify two numbers summing up to 9 . Their guesses regarding the vote distribution did not have to comply with that restriction, due to the possibility of some subjects ultimately abstaining.
} 
one of these guesses was randomly chosen for each subject and the subject was paid a $\$ 10$ bonus for that guess being correct.

Decisions and Payoffs. After subjects report their beliefs, each decides whether to abstain, vote red, or vote blue. Voting (for either red or blue) entails a cost of either 25 cents or 50 cents. ${ }^{15}$ Once all decisions are received, each group's votes are tallied and the alternative receiving the majority of votes is selected (ties broken randomly). Each subject for whom the color of the private draw coincides with the selected alternative receives $\$ 2$ for that period, while others receive no additional payments. The resulting per-period payoff is a reward corresponding to the selected alternative ( $\$ 0$ or $\$ 2)$ minus any cost incurred by voting.

To summarize, the experiments employ a $3 \times 2$ design based on variations in the information available to voters regarding the underlying distribution of preferences and the voting participation costs. Each experimental session implemented one of the information treatments (No Polls, Perfect Polls, or Lab Polls). Within most sessions, the initial 10 periods have costs set at 50 cents and are followed by 10 periods in which participation costs are set at 25 cents. ${ }^{16}$ In order to check for order effects, we ran several sessions in each information treatment with the order of costs reversed (namely, in two groups corresponding to the No Polls treatment and in three groups corresponding to each of the Perfect Polls and Lab Polls treatments). These "reverse order" sessions led to qualitatively identical insights as our baseline treatments. In order to keep the discussion focused, we report results aggregated across all sessions. ${ }^{17}$

The experiments were conducted at the California Social Sciences Experimental Laboratory (CASSEL) at UCLA. Overall, 198 subjects participated. The average payoff per subject in the No Polls treatment was $\$ 29.4$, the average payoff per subject in the Perfect Polls treatment was $\$ 31.9$, while the corresponding average in the Lab Polls treatment

\footnotetext{
${ }^{15}$ These costs were common and known to all subjects in the beginning of the round.

${ }^{16}$ Notice that the size of the bonus for correct guesses is sufficiently small as to make group behavior aimed at achieving the bonus particularly costly. In fact, while subjects had an accurate general perception of outcomes, their rates of correct guesses were very low, always lower than $10 \%$. We return to this point in Section 4.3.

${ }^{17}$ Separate analysis of the sessions in which rounds with voting costs of 25 cents preceded the rounds with voting costs of 50 cents is available from the authors upon request.
} 
was $\$ 30.1 .^{18}$ In addition, each subject received a $\$ 5$ show-up fee. Table 1 summarizes the details of our design.

\begin{tabular}{lccccccc}
\hline \hline & $\begin{array}{c}\text { Number of } \\
\text { Subjects }\end{array}$ & Groups & $\begin{array}{c}\text { Group } \\
\text { Size }\end{array}$ & $\begin{array}{c}\text { Known } \\
\text { Jar }\end{array}$ & $\begin{array}{c}\text { Polls } \\
\text { Run }\end{array}$ & $\begin{array}{c}\text { Probablity of } \\
\text { Belonging to Majority }\end{array}$ & $\begin{array}{c}\text { Maximal } \\
\text { Prize }\end{array}$ \\
\hline No Polls & 63 & 7 & 9 & No & No & $2 / 3$ & $\$ 2$ \\
Perfect Polls & 72 & 8 & 9 & Yes & No & $2 / 3$ & $\$ 2$ \\
Lab Polls & 63 & 7 & 9 & No & Yes & $2 / 3$ & $\$ 2$ \\
\hline
\end{tabular}

Table 1: Experimental Design

\section{Discussion of the Experimental Design}

There are several innovations our experimental design introduces relative to existing experimental work on participation. First, we elicit beliefs directly. Second, we allow for pre-election polls (importantly, ones whose role is not solely to ease coordination). Third, in all our environments there is some uncertainty, even when some form of polls is introduced.

There are some important design choices that are worth discussing. Our belief elicitation procedure entails subjects predicting the lead of the preferred candidate and the number of individuals of each preference type. This technique is different than that involving quadratic scoring rules for incentivizing truthful reports, which is commonly utilized in the experimental literature (see Gneiting and Raftery, 2007 for a review of proper incentives for belief elicitation). It is important to note that quadratic scoring rules require subjects to report a vector of beliefs over a set of plausible events. They are therefore practical when the set of plausible events is not too large. In our setting, the number of possible leads of the preferred candidate is a number between 0 and 9 . The number of possible outcomes, comprised of the number of participants and the distribution of votes, is far larger. ${ }^{19}$ The main advantage of our method is that it is simple. Furthermore, it is not sensitive to risk aversion as are quadratic scoring rules. Last, when subjects report expected leads, this elicitation process allows us to deduce the probability of pivotality

\footnotetext{
${ }^{18}$ These numbers correspond to the sum of the 20 period payoffs and the potential $\$ 10$ bonus payment for reporting a correct belief in the (randomly) chosen period and question.

${ }^{19}$ For any number $k$ of participants, there are $k+1$ possible leads of one candidate over the other, and so the overall number of outcomes is given by $1+2+\ldots+10=55$.
} 
from the reports of both lead and preference distribution (see Section 4.2).

Another design choice pertains to the discreteness of costs. While having a few discrete cost levels is in line with much of the experimental literature, an alternative design would have costs as a continuous parameter. A subject would then effectively need to decide on a threshold cost below which participation would be selected (much as in Levine and Palfrey, 2007). While this would be a very reasonable alternative design, we chose the discrete cost setting since it allows subjects to learn about the game itself more quickly indeed, when costs are continuously determined, the likelihood of facing two similar costs in any two periods is low and many periods need to be run in order for subjects to get experience with the game itself. In fact, as we will see (in Section 4.3), there was rather limited learning in all of our sessions.

\section{Theoretical Predictions}

Our experimental design is in line with the model proposed by Goeree and Großer (2007). Formally, consider a group of $n \geq 2$ individuals (subjects, committee members, political voters, etc.) who collectively choose one of two alternatives, red or blue. This can be understood as a metaphor for a choice between two political candidates, investment alternatives, etc. Each individual experiences a cost $c>0$ if she participates and no cost if she doesn't. The chosen alternative is determined using simple majority rule among the votes cast by all individuals who participated, where a tie leads to a random draw of one of the alternatives. An individual's utility is $V$ if her preferred alternative wins and 0 otherwise.

At the outset, a state of nature is chosen randomly from $\{R, B\}$ (experimentally corresponding to a red or blue jar; metaphorically, to a state in which one alternative or candidate is more popular than another). Both states are a-priori equally likely. If the

state is $R$, each individual receives an $r$ 'badge' with probability $p \geq 1 / 2$ and a $b$ badge with probability $1-p$. Similarly, when the state is $B$, each individual receives a $b$ badge with probability $p$ and an $r$ badge with probability $1-p$. An individual receiving an $r$ badge prefers the alternative red (and receives no utility from the alternative blue being 
selected), while an individual with a $b$ badge prefers the state blue.

The main parameter for this study is how much agents know about the selected state: without polls, only the prior; with perfect polls, the realized state; with lab polls, a noisy statistic about the realized state.

\subsection{No Access to Polls}

When agents are uninformed of the realized state, all are ex-ante symmetric. We focus on symmetric Bayesian Nash equilibria. Since $c>0$ and there are only two alternatives, whenever agents participate, they vote for their most preferred candidate.

Denote by $P_{p i v}(k)$ the probability that an agent is pivotal when $k$ other agents participate. If no other agent participates, an individual is certainly pivotal: $P_{\text {piv }}(0)=1$. When one other agent participates, the individual is pivotal only when the other agent has opposing preferences, $P_{\text {piv }}(1)=1 / 2$. For any $j=1, \ldots,\lfloor(n-1) / 2\rfloor,{ }^{20}$

$$
P_{p i v}(2 j)=\left(\begin{array}{c}
2 j \\
j
\end{array}\right) p^{j}(1-p)^{j} \text { and } P_{p i v}(2 j+1)=\left(\begin{array}{c}
2 j+2 \\
j+1
\end{array}\right) p^{j+1}(1-p)^{j+1} \text {. }
$$

Notice that an agent is pivotal either when a vote by her would create a tie (avoiding her preferred alternative being defeated), or when a vote by her would break a tie (and lead to her preferred alternative being selected). Since a tie is associated with a $50-50$ chance of either alternative being selected, the expected benefit from voting when pivotal is $V / 2$.

Whenever $c>V / 2$, costs outweigh the maximal possible benefit of voting and the unique symmetric equilibrium has no agent participating.

Whenever $c \leq P_{\text {piv }}(n-1) * V / 2$, the benefits of voting outweigh the costs even when all other agents participate for sure. In that case, the unique symmetric equilibrium would entail full participation.

For intermediate costs, symmetric equilibria involve agents mixing between voting and abstaining. Indifference between the two implies that the value of voting precisely equals its cost $c$. The more likely are others to vote, the higher are the incentives to free-ride and

\footnotetext{
${ }^{20}\lfloor x\rfloor$ denotes the greatest integer $k$ such that $k \leq x$.
} 


\begin{tabular}{lccccccc}
\hline \hline & \multicolumn{3}{c}{ No Polls } & \multicolumn{4}{c}{ Perfect Polls } \\
\hline & Vote & Expected & Expected & Vote Prob if & Vote Prob if & Expected & Expected \\
& Prob & Costs & Welfare & Majority & Minority & Costs & Welfare \\
\hline Cost $=25$ & 0.61 & 137 & 1071 & 0.70 & 1 & 180 & 1012 \\
Cost $=50$ & 0.21 & 95 & 995 & 0.19 & 0.39 & 117 & 899 \\
\hline
\end{tabular}

Table 2: Theoretical Predictions

abstain. The following proposition characterizes the unique symmetric equilibrium in our setting:

\section{Proposition 1 (No Polls - Equilibrium Participation)}

For participation costs $c \in\left(P_{\text {piv }}(n-1) * V / 2, V / 2\right)$, in the unique symmetric Bayesian Nash equilibrium, all agents participate with probability $\gamma^{*}(n, p, c) \in(0,1)$ given by:

$$
\frac{V}{2} * \sum_{k=0}^{n-1}\left(\begin{array}{c}
n-1 \\
k
\end{array}\right)\left(\gamma^{*}(n, p, c)\right)^{k}\left(1-\gamma^{*}(n, p, c)\right)^{n-1-k} P_{p i v}(k)=c
$$

and all those participating vote sincerely for their preferred alternative. Furthermore, $\gamma^{*}(n, p, c)$ is decreasing in $c$.

In our experiments, $V=\$ 2$, we consider $n=9, p=2 / 3$, and participation costs that are $c=25$ or $c=50$ cents. The left panel of Table 2 contains the resulting equilibrium voting probabilities. In addition, Table 2 reports the resulting expected participation costs (for the group) and the resulting expected collective welfare, calculated as the difference between the overall expected rewards for individuals and the costs incurred by the group.

\subsection{Introducing Polls}

We consider polls that reveal to the electorate the underlying distribution of preferences, i.e., all individuals know precisely which state $R$ or $B$ prevails (Perfect Polls treatment).

As before, when costs are sufficiently low, all agents participate, while when costs are high enough, no agents participate. For intermediate costs, at least some of the agents, depending on their preferences, will participate with some probability. 
Suppose, for instance, that the realized state is $B$. Focusing on intermediate costs, we consider quasi-symmetric Bayesian Nash equilibria. These are equilibria in which all agents who share a preferred alternative (red or blue) use the same strategy. Since blue is the a-priori majority preference, the pivotality conditions now need to be spelled out for each 'type' of individual, one who prefers red or one who prefers blue, separately. In order for the text of this paper to remain focused, we do not spell out the pivotality conditions that arise. The following proposition characterizes the unique quasi-symmetric equilibrium (in which all individuals who prefer the same alternative use the same strategy), assuming the realized state is $B$.

\section{Proposition 2 (Perfect Polls - Equilibrium Participation)}

For participation costs $c \in\left(P_{\text {piv }}(n-1) * V / 2, V / 2\right)$, in the unique quasi-symmetric Bayesian Nash equilibrium, the participation probabilities for those preferring $B$ and $R$ are given by $\gamma_{B}^{*}=\gamma^{*}\left(n, c, \frac{1}{2}\right) /(2 p)$ and $\gamma_{R}^{*}=\gamma^{*}\left(n, c, \frac{1}{2}\right) /(2(1-p))$ when $c \geq c_{\text {crit }}(p)$, while $(1-p) / p<$ $\gamma_{B}^{*} \leq 1$ and $\gamma_{R}^{*}=1$ when $c<c_{\text {crit }}(p)$, where

$$
c_{c r i t}(p)=\sum_{l=0}^{n-1}\left(\begin{array}{c}
n-1 \\
l
\end{array}\right)\left(\begin{array}{c}
l \\
\lfloor l / 2\rfloor
\end{array}\right)(1-p)^{l}(2 p-1)^{n-l-1} .
$$

A few notes are in order. First, if all agents vote with some probability, notice that the majority voters, those who prefer blue, should vote with lower probability than the minority voters. Indeed, for all agents the cost of participation is given by $c$. In equilibrium, all agents must equate the value of participating with its cost. Since the size of the majority is, by definition, greater than that of the minority, it must be that minority voters participate with greater propensities. ${ }^{21}$

This has a stark impact on outcomes. Indeed, since all voters, both in the majority and in the minority, equate the marginal benefits of voting with the same cost $c$, elections are likely to be 'toss-up' elections, in which alternatives are equally likely to be selected.

\footnotetext{
${ }^{21}$ When costs are sufficiently low, the incentives to vote increase, and minority voters ultimately vote with certainty. This is the case corresponding to $c \leq c_{c r i t}(p)$. Note that Goeree and Großer (2007) cover only the case $c \geq c_{c r i t}(p)$.
} 
In terms of welfare, information induces minority voters to participate excessively. This has two negative effects. First, participation costs are disbursed. Second, the alternative preferred by the majority is less likely to be selected. In other words, welfare decreases when more information is distributed in the population. ${ }^{22}$

The resulting unique quasi-symmetric Bayesian-Nash equilibrium probabilities for participation for majority and minority voters (say, for $b$ - and $r$-individuals when $B$ is the underlying state) are reported in the right panel of Table 2. We also report the resulting expected collective costs and expected welfare for the group.

\subsection{Lab Polls}

Our Lab Polls treatment does not mimic any theoretical environment that we are aware of. Unlike most theoretical models studying polls (see, e.g., Coughlan, 2000 or Goeree and Großer, 2007), in this treatment we do not restrict subjects to comply with the behavior announced at the polling stage. We avoid such restrictions in order to emulate 'real-world' polling instruments. In fact, one of our goals is to inspect subjects' (unconstrained) reports in the polling stage. This creates a relatively complicated environment, in which voters may choose to be either truthful or strategic in the polling stage of the game. In addition, they can consequently decide to follow their intentions or adjust their behavior after poll results are revealed. ${ }^{23}$

Certainly, this environment admits a babbling equilibrium, in which agents do not condition their reports at the polling stage on their preferences and follow the equilibrium of the No Polls treatment at the voting stage.

Other than this equilibrium, a natural class of equilibria to consider is that in which agents do not mix at the polling stage (but potentially mix at the voting stage). If we impose symmetry (so that $b$ - and $r$-individuals behave in a symmetric fashion - reporting

\footnotetext{
${ }^{22}$ All of these qualitative results would follow through if participation costs were randomly determined, as long as the distributions from which costs were drawn did not depend on the alternative preferred by an agent.

${ }^{23}$ Notice that this game involves, in principle, rather intricate considerations. Reactions to polls may depend on the precise distribution of reports of intended votes for either alternative and abstention. In that sense, an agent may always be effectively pivotal in the polling stage, her reports may always affect the distribution of ultimate outcomes.
} 
either abstention, the alternative they prefer, or the alternative they do not support in the polling stage), the analysis simplifies substantially. Indeed, all agents abstaining constitutes part of a babbling equilibrium. Otherwise, without loss of generality, assume that agents report truthfully their preferences at the polling stage. ${ }^{24}$ In that case, polls reveal the realized distribution of preferences. The voting stage is then tantamount to a Palfrey and Rosenthal (1983) setting. In particular, behavior at the voting stage must coincide with an equilibrium of the corresponding Palfrey and Rosenthal (1983) game. In our setting, we use numerical calculations to show that truthful reporting in the polling stage is never part of an equilibrium. ${ }^{25}$ In other words, the babbling equilibrium is the only equilibrium that does not involve mixing at the polling stage.

Intuitively, when the realized distribution is known, the greater the number of supporters of one alternative, the lower the probability of participation by supporters of that alternative. Therefore, lying at the polling stage serves to lower participation rates by the supporters of the alternative the subject prefers less and can therefore be beneficial.

The analysis of the entire set of equilibria that allow for mixing at the polling stage is beyond the scope of this paper. ${ }^{26}$ Nonetheless, we return to some indicators of the extent to which subjects are best responding in our data when we discuss the results from the Lab Polls treatment.

\section{Results: Voting Behavior}

In this section, we present the voting patterns observed in our data. We first describe the overall voting propensities of majorities and minorities across sessions. We then consider information and consequent beliefs as channels explaining voting behavior.

\footnotetext{
${ }^{24}$ If all agents mis-report their preferences at the polling stage, the same information is transmitted in the group up to a relabeling of the alternatives.

${ }^{25}$ We calculated the equilibria corresponding to all distributions of preferences in our setting in the induced (second-stage) voting games. For certain distributions, there are multiple equilibria. Therefore, we considered all selections (mappings from realized distributions to a particular equilibrium in the induced game at the voting stage) and reactions to polls containing an abstention. We then calculated the incentives to deviate from reporting truthfully at the polling stage and following the corresponding equilibria prescriptions at the voting stage.

${ }^{26}$ The number of pure actions, even imposing symmetry, is vast. For any action choices at the polling stage, we need to specify the participation decisions for any possible realization of poll reports.
} 


\subsection{Turnout}

Table 3 contains the observed voting propensities as a function of whether an individual is part of the expected minority or majority, when such indication exists (all standard errors appearing in parentheses). The comparative statics with respect to costs hold across conditions: higher costs generating lower participation. However, in both our Perfect Polls and Lab Polls treatments, minorities participate less than majorities (differences significant at any reasonable level). Furthermore, the availability of information reduces the probability of minority participation and increases the probability of majority participation.

\begin{tabular}{lccccc}
\hline \hline & No Polls & \multicolumn{2}{c}{ Perfect Polls } & \multicolumn{2}{c}{ Lab Polls } \\
\cline { 2 - 6 } & $\begin{array}{c}\text { Observed } \\
\text { Vote Prob }\end{array}$ & $\begin{array}{c}\text { Observed } \\
\text { Vote Prob if } \\
\text { Majority }\end{array}$ & $\begin{array}{c}\text { Observed } \\
\text { Vote Prob if } \\
\text { Minority }\end{array}$ & $\begin{array}{c}\text { Observed } \\
\text { Vote Prob if } \\
\text { Majority* }\end{array}$ & $\begin{array}{c}\text { Observed } \\
\text { Vote Prob if } \\
\text { Minority* }\end{array}$ \\
\cline { 2 - 6 } Cost $=25$ & $0.55(0.05)$ & $0.63(0.04)$ & $0.38(0.05)$ & $0.58(0.05)$ & $0.40(0.05)$ \\
Cost $=50$ & $0.43(0.04)$ & $0.52(0.05)$ & $0.27(0.04)$ & $0.50(0.05)$ & $0.31(0.04)$ \\
\hline * Majority and minority correspond to those observed in the lab poll. & & \\
\hline
\end{tabular}

Table 3: Observed Participation Propensities

Excessive voting by members of the majority group is a well-known result that was documented in several other studies, in which majority membership is transparent (see Duffy and Tavits, 2008, Großer and Schram, 2010, and Kartal, 2012). Even though this result goes against the predictions of the pivotal voter model, the previous literature does not suggest the reason why we observe majorities voting more than minorities. Our design allows us to investigate this phenomenon in depth since in addition to the voting propensities we also elicit the beliefs that voters hold regarding election outcomes. Such beliefs data are necessary to disentangle whether excessive voting by majority group members is due to systematic mistakes in beliefs or to a failure to best respond vis-à-vis beliefs that are accurate. 


\subsection{Response to Information}

In order to understand the mechanism generating the observed participation rates, subjects' reports regarding their beliefs are particularly useful. Since behavior across costs appears very similar for all of our treatments, for simplicity, in the remains of the paper, we present results aggregated across costs. ${ }^{27}$

In the No Polls treatment, agents' participation rates do not differ significantly when elections are predicted to be toss-up elections (i.e., alternatives are tied or their support differs by one vote) or not. However, when information is available in the Perfect Polls and Lab Polls treatments, elections that are perceived to be close generate significantly greater participation than others. ${ }^{28}$ At first blush, these results seem in line with the pivotal voter model - agents participate at greater frequencies when they perceive themselves as pivotal. They are consistent with the insights of some of the experimental literature that inspects the pivotal voter model and considers different likelihoods of close elections (see, e.g., Duffy and Tavits, 2008 and Levine and Palfrey, 2007).

Our design allows us to unfold the responses to different events corresponding to elections that are not close - those in which the preferred alternative is predicted to win with a landslide, and those in which the opposing candidate is predicted to win with a large victory margin. ${ }^{29}$ Figure 1 depicts subjects' voting propensities as a function of their predictions regarding the lead of their preferred candidate (where light gray bars correspond to the frequency of the different guess leads in our data). ${ }^{30}$

Figure 1 illustrates behavior that is not naturally aligned with the prescriptions of the pivotal voter model. While voting propensities are lower when the opposing candidate is predicted to exhibit a large margin of victory relative to those corresponding to close

\footnotetext{
${ }^{27}$ All of the observations hold true when separating treatments by costs. These separate analyses are available from the authors upon request.

${ }^{28}$ In the Perfect Polls treatment, participation rates were 0.59 and 0.49 when elections were perceived to be close and not, respectively. The difference between the two rates is significant at the $10 \%$ level. In the Lab Polls treatment, participation rates were 0.62 and 0.42 when elections were perceived to be close and not, respectively, with differences between the two rates being significant at the $5 \%$ level. The statistical significance is assessed using the Wilcoxon rank-sum test with one observation per subject per category.

${ }^{29}$ In what follows, we call elections that are predicted not to be close, i.e., predicted to have a winner's lead of two or more votes, landslide elections.

${ }^{30}$ In Figure 1, we report only events that occurred at least 10 times over all experimental elections.
} 


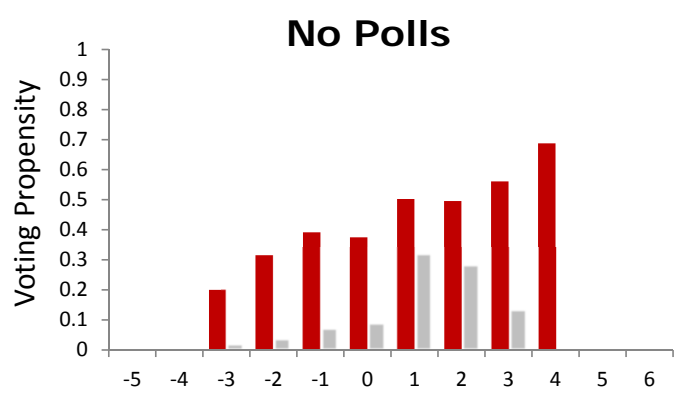

Guess Lead of Preferred Alternative

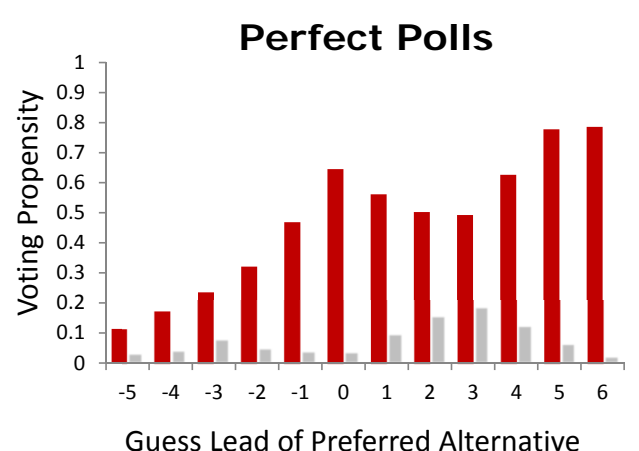

Guess Lead of Preferred Alternative

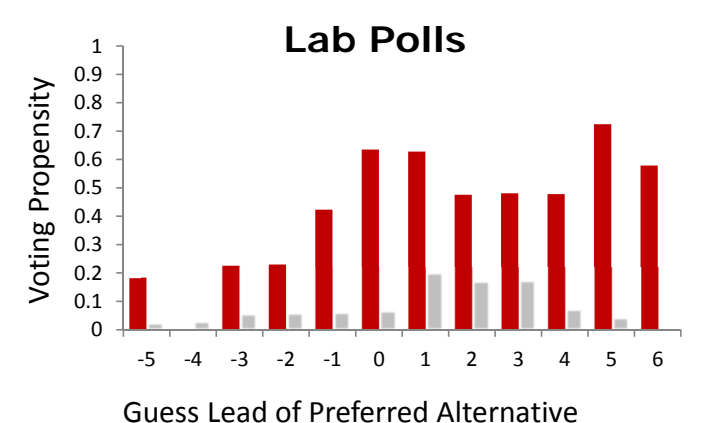

Guess Lead of Preferred Alternative

Figure 1: Voting Propensities as a Function of Beliefs

elections, the propensities to vote when the preferred alternative is predicted to have a landslide win do not appear to be very different than those observed when elections are predicted to be close. This is echoed statistically. Across sessions, voting propensities are significantly lower when the preferred candidate is predicted to have a substantial loss (with the winning candidate having a lead of at least two votes) relative to the propensities to vote when the election is predicted to be close. ${ }^{31}$ These differences are all significant at the $1 \%$ level. However, across treatments, when focusing on the last 10 periods in all

\footnotetext{
${ }^{31}$ When the preferred candidate is predicted to lose with a substantial margin, voting propensities are $0.29,0.26$, and 0.22 in the No Polls, Perfect Polls, and Lab Polls treatments, respectively. The corresponding rates for elections that are predicted to be close are $0.46,0.59$, and 0.62 , respectively.
} 
sessions, propensities are not significantly different between predicted close elections and elections in which the preferred alternative is predicted to win with a landslide. ${ }^{32} \mathrm{We}$ stress that when looking at the last 10 periods in all sessions, the responses to perceived election leads are statistically indistinguishable across treatments. That is, our treatments affect subjects' perceptions of the election outcome, but not the mapping between these beliefs and their ultimate voting choices.

These results are mirrored by the response to the polling information in our Lab Polls treatment, i.e. the aggregate statistics that emerged from subjects' own poll responses regarding their intended actions. When the lab poll suggested the preferred alternative would experience a substantial loss, the voting propensity was 0.29 . When the lab poll suggested a toss-up election, the voting propensity was 0.60 , different than the former rate at the $1 \%$ level, but not significantly different than the rate of 0.49 observed when a landslide victory for the preferred alternative was suggested by the polls.

One could naturally wonder whether reported beliefs are at all accurate. Indeed, if, say, agents tended to report exaggerated beliefs regarding the likelihood of their preferred candidate winning with a large margin, ultimate behavior could still approximate that prescribed by the pivotal voter model. Figure 2 depicts the predicted lead as a function of the realized lead of the preferred alternatives. As can be seen, the No Polls treatment exhibits fairly poor accuracies of beliefs (with some advantage given to the preferred alternative). This should be expected since subjects do not receive any information that is indicative of the composition of their group. ${ }^{33}$ However, subjects are fairly accurate in the Perfect Polls and Lab Polls treatments, at least for moderate leads (where the majority of our data lays). When actual leads are extreme, subjects are more conservative in their beliefs, but the linkage between beliefs and realized leads is symmetric across losses and

\footnotetext{
${ }^{32}$ When the preferred candidate is predicted to win with a substantial margin, voting propensities in the last 10 rounds are 0.52,0.55, and 0.50 in the No Polls, Perfect Polls, and Lab Polls treatments, respectively. These voting propensities are not significantly different from one another.

${ }^{33}$ The fairly consistent predicted lead of one vote for the preferred alternative can be explained as follows. Each subject's posterior that the selected jar color matches their preference is $2 / 3$. Therefore, the probability that any other individual shares their preferences is given by $2 / 3 * 2 / 3+1 / 3 * 1 / 3=$ $5 / 9$. In particular, the expected number of individuals preferring the alternative the subject prefers is $1+5 / 9 * 8=5.44$, while the expeced number of subjects preferring the other alternative is $4 / 9 * 8=3.55$. Recall that individual turnout rates were between $43 \%$ and $55 \%$ (depending on costs). These would translate into an expected lead of approximately one vote for the preferred alternative.
} 


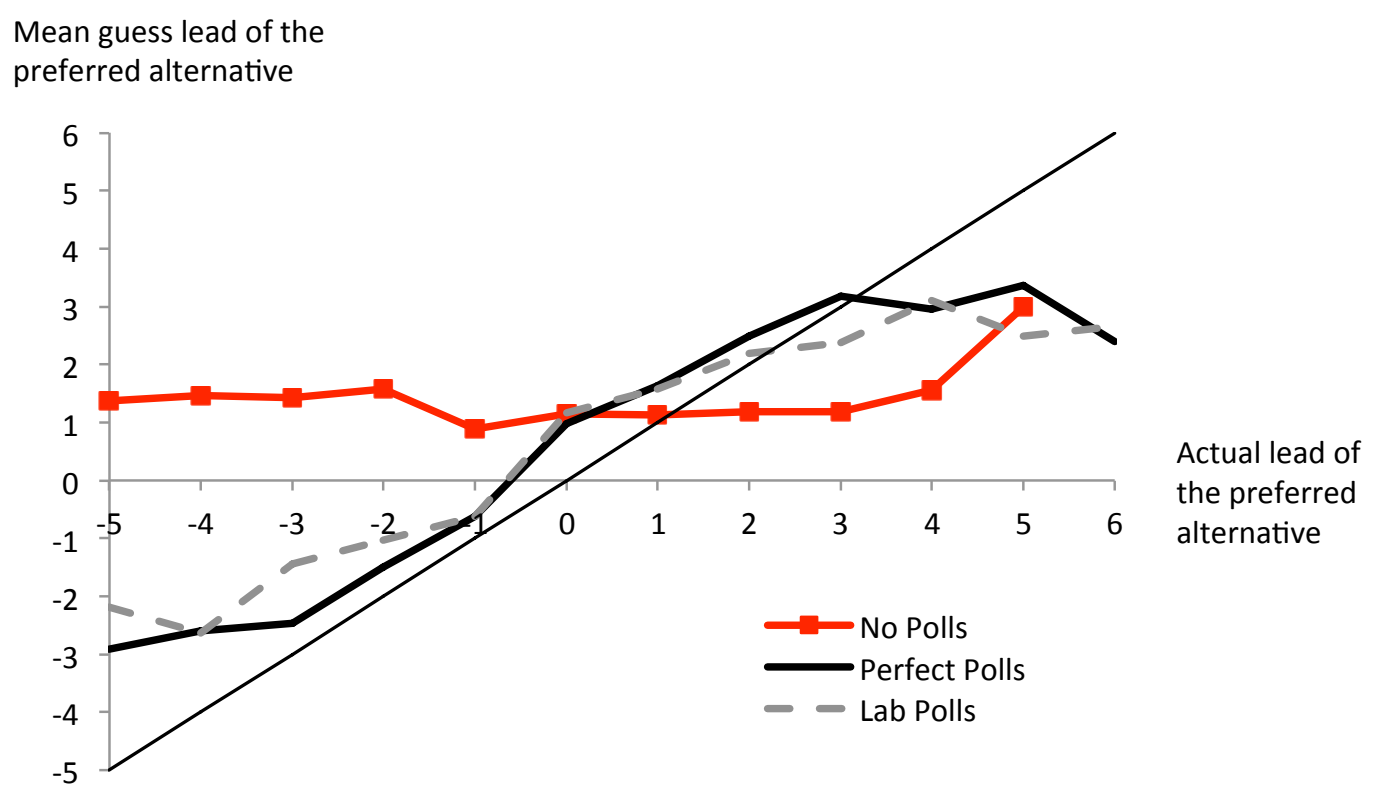

Figure 2: Beliefs Accuracies

victories of the preferred alternatives. In particular, distortions in beliefs cannot reconcile in and of themselves the pivotal voter model with the participation responses to beliefs we observe. ${ }^{34}$ Furthermore, when splitting our population of subjects into those that tended to hold extreme beliefs and those who held moderate beliefs on average, observed behavior for either group looks indistinguishable than the aggregate behavior depicted in Figure 1, implying that the observed response to information is not driven by a sub-group of subjects holding less accurate beliefs. ${ }^{35}$

Last, we mention an alternative way by which to consider subjects' responses to information. Recall that we elicited subjects' predictions regarding both the composition of groups as well as their predictions regarding the realized lead of either alternative. Suppose that reported predicted leads were expectations derived from some perceived probabilities of participation by either type of voter. We can then deduce these perceived

\footnotetext{
${ }^{34}$ We stress that learning is not at the root of the belief patterns we observe. In particular, if we restrict attention to the last 10 periods of each session, beliefs remain accurate.

${ }^{35}$ Formally, focusing on the Perfect Polls treatment, we associated each subject with a score corresponding to the average lead of their preferred candidate conditional on being part of the majority. We then split our sample into subjects with a score lower than 3 and those with a score higher than 3 (corresponding to $61 \%$ and $39 \%$ of subjects, respectively). The results reported in this section replicate for each of the two groups separately (analysis available from the authors upon request).
} 
probabilities and calculate the induced probability of being pivotal for each individual. Response to information can then be seen through the propensity to vote as a function of these induced probabilities of being pivotal. Such a calculation generates very similar insights to the ones described above. While a high probability of pivotality is associated with greater turnout than a slightly lower probability of pivotality, the association is in no way monotonic globally. In fact, the highest turnout rates correspond to moderate induced probabilities of being pivotal. ${ }^{36}$

\subsection{Individual Regression Analysis}

We use regression analysis to investigate individual behavior. While the previous section illustrated the link between participation and beliefs, we are interested in the relative effects of other factors. In particular, we want to inspect whether behavior in specific groups evolved in different ways throughout the experiment.

For each treatment, we run a Probit regression predicting the dependence of participation decisions on various explanatory variables, clustering standard errors by individuals. Table 4 contains our estimations.

We first note that there are no group-specific effects in any of the three treatments. ${ }^{37}$ Second, there are no time effects, suggesting that behavior in our experiments exhibited very little learning. ${ }^{38}$

The regression analysis provides us with another opportunity to closely examine several predictions of the pivotal voter model. Among other things, this model suggests that an individual is more likely to participate when the voting costs are low, the composition lead of the preferred alternative is small, the lead of the majority group is small if the voter is a member of the majority group, or when the lead of the majority group is small when the voter is a member of the minority group. Indeed, the latter three types of

\footnotetext{
${ }^{36}$ For instance, in the Lab Polls treatment, turnout is $25 \%$ when the induced probability of being pivotal is between 0.95 and 1 , while it is $56 \%$ when the induced probability of being pivotal is between 0.25 and 0.35 .

${ }^{37}$ In all treatments, all dummy variables that indicate a particular group of subjects are not significantly different from zero with p-values above $10 \%$.

${ }^{38}$ This provides justification for the way we report our results throughout the paper, pooling observations from all periods of the experiment.
} 


\begin{tabular}{|c|c|c|c|c|c|c|}
\hline \multirow[b]{2}{*}{ Group 2} & \multicolumn{2}{|c|}{ No Polls } & \multicolumn{2}{|c|}{ Perfect Polls } & \multicolumn{2}{|c|}{ Lab Polls } \\
\hline & 0.14 & {$[0.13]$} & -0.11 & {$[0.09]$} & 0.06 & {$[0.09]$} \\
\hline Group 3 & -0.01 & {$[0.11]$} & -0.01 & {$[0.09]$} & 0.07 & {$[0.11]$} \\
\hline Group 4 & 0.16 & {$[0.10]$} & -0.02 & {$[0.11]$} & $0.25 * *$ & {$[0.10]$} \\
\hline Group 5 & 0.07 & {$[0.11]$} & 0.06 & {$[0.09]$} & 0.08 & {$[0.12]$} \\
\hline Group 6 & 0.08 & {$[0.14]$} & 0.02 & {$[0.10]$} & 0.04 & {$[0.11]$} \\
\hline Group 7 & -0.01 & {$[0.13]$} & -0.03 & {$[0.10]$} & 0.18 & {$[0.11]$} \\
\hline Group 8 & & & -0.06 & {$[0.07]$} & & \\
\hline Period & -0.0005 & {$[0.01]$} & 0.005 & {$[0.01]$} & -0.006 & {$[0.01]$} \\
\hline High Cost of Voting & $-0.22 * * *$ & {$[0.05]$} & $-0.13 * * *$ & {$[0.03]$} & $-0.08 * * *$ & {$[0.03]$} \\
\hline Cumulative profit at $\mathrm{t}-1$ & -0.0001 & {$[0.0001]$} & -0.00004 & [0.00008] & 0.00006 & {$[0.0001]$} \\
\hline Profit at t-1 & $-0.0006 \quad * *$ & {$[0.0003]$} & -0.001 & {$[0.0007]$} & -0.0002 & {$[0.0003]$} \\
\hline Voted at t-1 & -0.04 & {$[0.07]$} & -0.04 & {$[0.07]$} & 0.05 & {$[0.07]$} \\
\hline Voted and Won at t-1 & $0.32 * * *$ & {$[0.06]$} & $0.40 * * *$ & [0.13] & $0.17 *$ & {$[0.10]$} \\
\hline Abstained and Won at t-1 & -0.09 & {$[0.07]$} & 0.002 & [0.13] & -0.09 & {$[0.07]$} \\
\hline Composition lead of the preferred alternative (belief) & 0.007 & {$[0.01]$} & $-0.04 * * *$ & {$[0.01]$} & $-0.03 * *$ & {$[0.01]$} \\
\hline Lead of the majority if in majority (belief) & 0.03 & {$[0.02]$} & $0.06 * * *$ & [0.02] & $0.03 * *$ & [0.02] \\
\hline Lead of the majority if in minority (belief) & $-0.13 * * *$ & {$[0.03]$} & $-0.15 * * *$ & [0.02] & $-0.14 * * *$ & [0.03] \\
\hline Lead of the preferred candidate (poll) & & & & & -0.006 & {$[0.01]$} \\
\hline predicted Probability to Vote (mean) & 0.48 & & 0.47 & & 0.47 & \\
\hline \# of obs. & 879 & & 1174 & & 1024 & \\
\hline Pseudo R-squared & 0.1674 & & 0.1984 & & 0.1501 & \\
\hline
\end{tabular}

Robust standard errors are reported in brackets (standard errors were clustered by individuals).

Group 1 is the baseline in all treatments. All regressions pertain to period 2 and on to allow for lagged variables.

For dummy variables (Group dummies, High Cost of Voting, Voted at t-1, and Voted and won at t-1) we report dF/dx for the discrete change from 0 to 1 .

We exclude subjects that either always participated or never participated throughout the experiment, and those whose guesses about the composition of the group and the expected number of votes were inconsistent.

$* * *$ - significant at $1 \%$ level, $* *$ - significant at $5 \%$ level, $*$ - significant at $10 \%$ level

Table 4: Probit Regressions Explaining Turnout (Marginal Effects Reported) 
events correspond to a greater probability that an individual vote would be pivotal in the election. Our data suggest that most but not all of these predictions hold true. In all three treatments, higher voting costs decrease participation probabilities and a greater lead of the alternative preferred by the majority decreases the probability that minority members participate. Moreover, in both treatments with polls, the propensity to vote declines with the composition lead of the preferred alternative. However, as illustrated in the previous section and contrary to the predictions of the pivotal voter model, in both poll treatments the lead of the majority group has a positive and significant effect on participation by majority group members.

Finally, in all treatments subjects are more likely to vote in the current election if they did so in the previous election and their preferred alternative won. This effect is reminiscent of reinforcement learning models, according to which people are more likely to choose strategies that achieved good results in the past rounds of the play (see Fudenberg and Levine, 1998 and references therein). However, this effect pertains only to active past participation - past abstention associated with victory of the preferred alternative has no significant effect on current participation.

\subsection{Alternative Models}

Before moving on to the discussion of the aggregate results and behavior of our subjects in the Lab Polls treatment, we discuss in this section alternative models that may account for the voting behavior reported above.

\section{Risk Aversion and Loss Aversion}

The pivotal voter model combined with risk or loss aversion cannot explain the behavior observed in our experiments. Indeed, suppose $p_{-1}$ and $p_{0}$ denote the perceived probability that, absent one's vote, the preferred alternative loses by one vote and ties with the other alternative respectively, and let $u$ denote agents' utility function. Then, the difference in utility terms between voting and not voting is given by:

$$
\frac{1}{2}\left(p_{-1}+p_{0}\right) u(V)+u(-c)
$$


where, recall, $V$ is the value of getting the preferred alternative selected and $c$ is the cost of voting and we normalize the utility of getting the less preferred alternative getting selected to be 0 . Both risk aversion - concavity of the function $u$, or loss aversion, which would diminish the absolute magnitude of $u(V) / u(-c)$, would then mute the value of voting. However, both would still suggest declining propensities to vote as the lead becomes very large, which we do not observe in the data. Results reported in Figure 1 and Table 4 indicate that propensities to vote are statistically indistinguishable with high leads from those of very close leads, which is incompatible with either loss or risk aversion.

\section{Regret}

There are several theories that incorporate regret motives into the calculus of voting. The original models of this sort, as in Ferejohn and Fiorina (1974), suggested that voters calculate the loss associated with various outcomes without estimating the probabilities of these outcomes and choose the option that minimizes regret. Such a model would predict the curves depicted in Figure 1 to be flat, which is not what we observe.

The more recent theoretical models of regret such as Loomes and Sugden (1982) and Sugden (1993) incorporate the idea that a decision-maker might feel regret for making a wrong choice, ex-post, after the state of the world is revealed to her. Applying this idea to political behavior, one may conjecture that voters may feel regret for having voted for the wrong candidate. ${ }^{39}$ However, notice that in our setup subjects know precisely which candidate delivers higher utility for them. Therefore, the only two possible types of regret that voters may experience in our setting are (1) the regret from voting when one could have abstained and (2) the regret from abstaining when one could have voted and changed the outcome of the election. Both types of regret may affect participation rates, but still imply that greater convictions in either loss or victory should correspond to lower voting propensities, which is not what we observe in our data.

\footnotetext{
${ }^{39}$ See Ortoleva and Snowberg (2014) who incorporate regret motives into an incomplete information model of voter turnout. In their setup voters support the candidate whose policy is more likely to be better for them conditional on the state of the world and abstain if neither of the candidates is much more likely to be better for them.
} 


\section{Ethical Voting}

Some recent work (see Feddersen, Gailmard, and Sandroni, 2009) has suggested that an important mechanism affecting individuals' participation decision is their perception of what is 'moral.' In those models, individuals get a utility benefit from taking an action that promotes overall welfare. In our setting, welfare is tied to the number of individuals preferring each alternative - the alternative having a majority support can naturally be interpreted as the 'moral' alternative and such a form of ethical voting would imply participation rates that are higher for larger majorities, and potentially go against one's own preference (when the predicted majority-preferred alternative is not one's own). However, this is not what we observe in our data in any of the three informational treatments. Indeed, the perceived composition of voters (how many are expected to be supporting either alternative) that we elicited is a good proxy for which alternative is more 'ethical.' Nonetheless, when controlling for the predicted lead one's preferred alternative is expected to have, the perceived composition of voters does little to explain turnout. ${ }^{40}$

\section{Voting with the Winner}

The increase in the propensity to vote associated with subjects' prediction of their preferred alternative's advantage is consistent with a model in which subjects respond not only to the probability of being pivotal but also have a desire to vote for the winner. There is a growing empirical literature that documents such a desire using field data from national elections. Herron (1998) analyzes micro-level data from the 1992 United States presidential election and finds that Clinton supporters who believed that Clinton was likely to win voted at higher rates than those who believed otherwise, while Bush supporters were significantly less likely to turn out if they held the same belief. Similarly, in the 2000 presidential election, a survey conducted under the American National Election Study revealed that of respondents who thought their preferred candidate would win by a large margin, $65 \%$ still went out to vote (authors' tabulation). In a similar spirit, the Target

\footnotetext{
${ }^{40}$ For instance, in the Lab Polls treatment, conditional on the belief that the election will end up in a landslide victory, voters that predict a small difference between the number of majority and minority supporters vote with probability $44 \%$, while those predicting a large difference between the number of majority and minority supporters vote with a smaller probability of $34 \%$. Similar behavior is observed in other informational treatments.
} 
Group Index Brasil study of 2003 interviewed 8,907 individuals between the ages of 20 and 64 . Of those, $13 \%$ agreed with the statement "I always vote for the probable winner in an election."

There are several theoretical papers that incorporate a desire for voting for the winner in a model of political behavior. The first such model is Hinich (1981), who considers a theory of voting in two candidates elections. Hinich derives voting rules that depend both on voters' subjective beliefs about the election outcome and their preferences over candidates. The main assumption is that voters' utility increases when voting for a winner and decreases when voting for a loser. Hinich argues that this assumption is no less plausible than the assumption that voters believe they can be pivotal.

More recently, two theoretical papers incorporate voters' desire to vote for the winner in the standard pivotal voter framework. Callander (2007) studies a sequential model of voting and shows that a desire to conform might induce momentum and bandwagons on the equilibrium path. In a companion paper, Callander (2008) investigates simultaneous elections and establishes that a desire to win creates multiple equilibria, some of which exhibit negative information aggregation - information aggregated in equilibrium helps the worse candidate get elected.

Our experimental data provide an opportunity to estimate the magnitude of this effect. Consider a modified version of agents' utilities from voting (borrowed from Callander, 2007, 2008). If agent $i$ votes for her preferred alternative, then her utility is given by:

$$
u_{i}=\frac{V}{2} \cdot \operatorname{Prob}[\text { preferred alternative wins }]+a \cdot \operatorname{Prob}[\text { voting for winner }]-c
$$

If agent $i$ abstains, her utility is:

$$
u_{i}=\frac{V}{2} \cdot \operatorname{Prob}[\text { preferred alternative wins }]
$$

Using this utility specification, we estimate the parameter $a$ that maximizes the likelihood of matching the voting pattern for each subject separately. That is, for each subject, based on her 20 decisions, we find the parameter $a$ that matches the largest number of these decisions. Since there is generally a range of such maximizing parameters $a$, in what 
follows we report the average value of $a$ for each subject. Figure 3 plots the cumulative distributions of estimated values of $a$ by subject in each information treatment. The range of $a$ in the figure is $[0,100]$. In terms of experimental tokens, the value of $V$ in our experiments was 200 , corresponding to $\$ 2$, so the maximal value of $a$ we observe corresponds to the reward from having the preferred alternative win.

Figure 3 illustrates substantial heterogeneity in subjects' voting behavior. Regardless of the information treatment, there is a significant group of subjects who base their voting decisions almost entirely on the probability of being pivotal (low values of $a$ ). At the same time, voting behavior of other subjects is heavily influenced by the desire to vote for the winner (high values of $a$ ). We note that the distributions of estimated $a$ parameters are similar across treatments, consistent with an underlying distribution of preferences as specified in the population. ${ }^{41}$

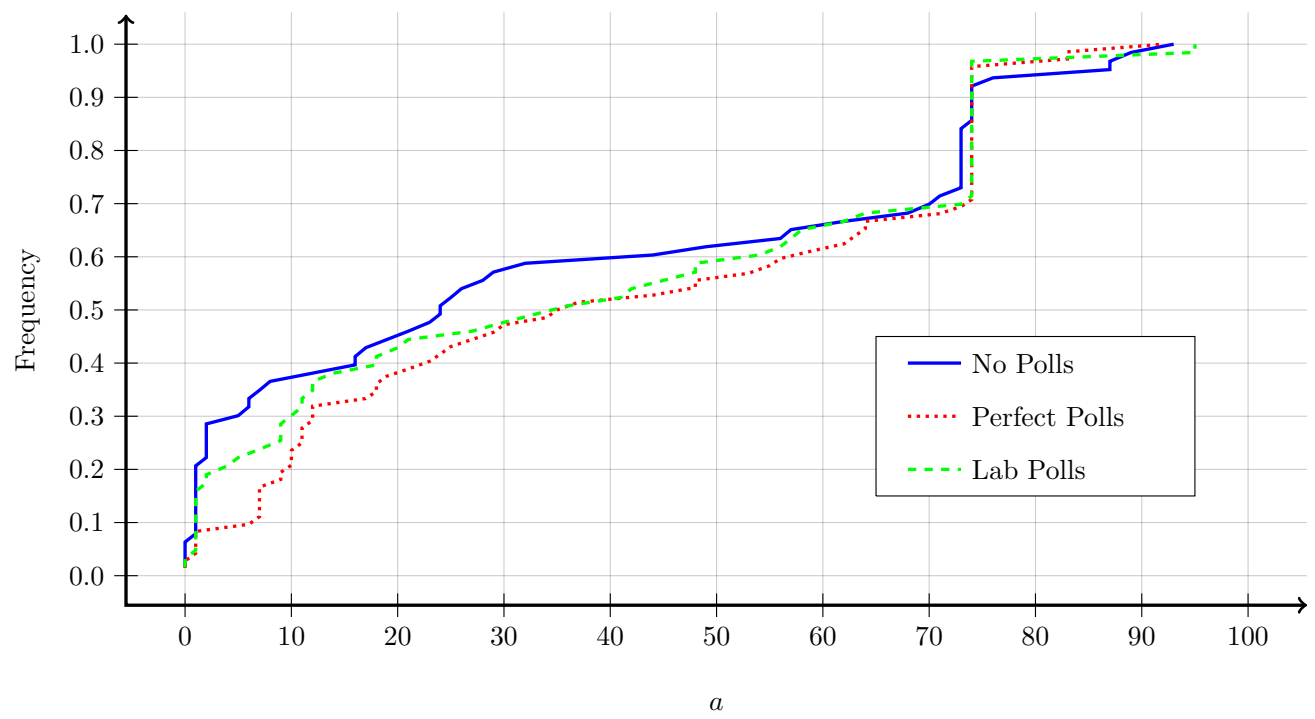

Figure 3: Cumulative Distributions of Estimated Values of $a$, by Treatment

\footnotetext{
${ }^{41}$ A non-parametric Kolmogorov-Smirnov test detects no statistical difference in the distribution of parameters $a$ between the No Polls and Lab Polls treatments $(p=0.465)$, as well as between the Perfect Polls and Lab Polls treatments $(p=0.461)$. There is, however, a difference between the No Polls and Perfect Polls treatments $(p=0.031)$. Indeed, in the No Polls treatment we observe a significantly higher percentage of subjects that have very low values of $a<10$ (about 40\%), while that percentage is only $20 \%$ in the Perfect Polls treatment.
} 


\section{Election Outcomes}

In this section, we describe how the behavioral patterns of voting identified in the Section 4 affect the aggregate election outcomes. We first discuss the distribution of votes allocated to each candidate and, in particular, the prevalence of very close elections as a function of the information available. We then consider the welfare consequences of the electorate having access to information via polls. ${ }^{42}$

Recall that the pivotal voter model predicts that information has an overall negative effect on the social welfare. This result is based on the observation that the pivotality condition requires the majority voters to vote with lower probability than the minority voters. This, in turn, results in an overall higher participation costs incurred by all voters, a higher likelihood of observing a toss-up election, and a lower chance of the majority-preferred alternative to be selected. However, as we documented in Section 4, the voting propensities of the majority group members is higher than that of the minority group members. Thus, the detrimental effects of information are put to question. In the remainder of this section, we will assess whether indeed a society is worse off when voters have access to polling data.

\subsection{The Emergence of Toss-up Elections}

Contrary to the prediction of the pivotal voter model, we find that toss-up elections (in which alternatives either tied or differed by one vote) occurred significantly more frequently in the No Polls treatment than in either of the two treatments in which information regarding the distribution of preferences was revealed. ${ }^{43}$ In fact, the No Polls treatment produces cumulative distributions that are first order stochastically dominated by those

\footnotetext{
${ }^{42}$ We note that there were no persistent biases toward the blue or red alternatives: behavior was not significantly different across the labels of the alternatives.

${ }^{43}$ Statistically, we use a probit regression to explain whether an election culminated in a toss-up outcome with dummy variables for treatments, while clustering observations by groups. For either cost, when the Toss-up dummy is regressed on the Perfect Polls dummy (or Lab Polls dummy), leaving the No Polls treatment as the baseline, we obtain a negative coefficient for the corresponding Polls dummy that is significant at the $5 \%$ level. When the Toss-up dummy is regressed on the Lab Polls dummy leaving the Perfect Polls treatment as the base group, we obtain a coefficient that is not significantly different from zero.
} 
generated by the other two treatments. ${ }^{44}$ Moreover, landslide elections appear more frequently when information regarding preferences is available. Finally, we note that the Perfect Polls and Lab Polls treatments generated very similar distributions of ultimate vote leads that are not significantly different from one another. ${ }^{45}$

\subsection{Welfare}

We now turn to the performance of elections with and without polls in terms of overall welfare and likelihood of selecting the majority-preferred alternative.

In terms of choosing the collectively optimal alternative, that favored by a majority, polls appear to have a positive effect. As the top panel of Table 5 suggests, especially for lower participation costs, the availability of Perfect or Lab polls assists somewhat in achieving the alternative favored by the majority. These differences are more pronounced when the group is closely divided (corresponding to type differences of 1 or 3). Participation costs are not significantly different across treatments as the second panel in Table 3 illustrates. In fact, in utility terms, group utilitarian welfare (accounting for payoffs from the selected alternative and the participation costs), is not significantly different across treatments. ${ }^{46}$ Notice that this result contrasts some of the basic insights from the theoretical work on polls that suggests the negative effects of polls (due to the increased propensity of the 'wrong' minority group to participate as we documented in Section 4).

We stress that had subjects used equilibrium strategies, with our volume of data, the ranking of welfare across treatments would likely correspond to the theoretical predictions and be statistically different. ${ }^{47}$

\footnotetext{
${ }^{44}$ The graphs are omitted for brevity and available from the authors upon request.

${ }^{45}$ To compare the distributions of vote leads of the winner between Perfect Polls and Lab Polls we used the same technique as for the comparison of the No Polls and Perfect Polls (Lab Polls) treatments described above (see Footnote 43).

${ }^{46}$ Welfare is not significantly different across treatments according to any standard parametric or nonparametric test clustering by groups.

${ }^{47}$ For instance, for participation costs of 50, simulating our experiment assuming that subjects use equilibrium strategies (with the number of subjects participating in our experiments) for 1,000,000 iterations leads to a likelihood exceeding $95 \%$ of group welfare without polls surpassing that with perfect polls. Performing the same simulations using subjects' experimental participation rates leads to a likelihood of less than $10 \%$ of group welfare without polls surpassing that with perfect polls. In particular, this suggests that it is not the particular experimental realizations of preferences that are driving our results.
} 


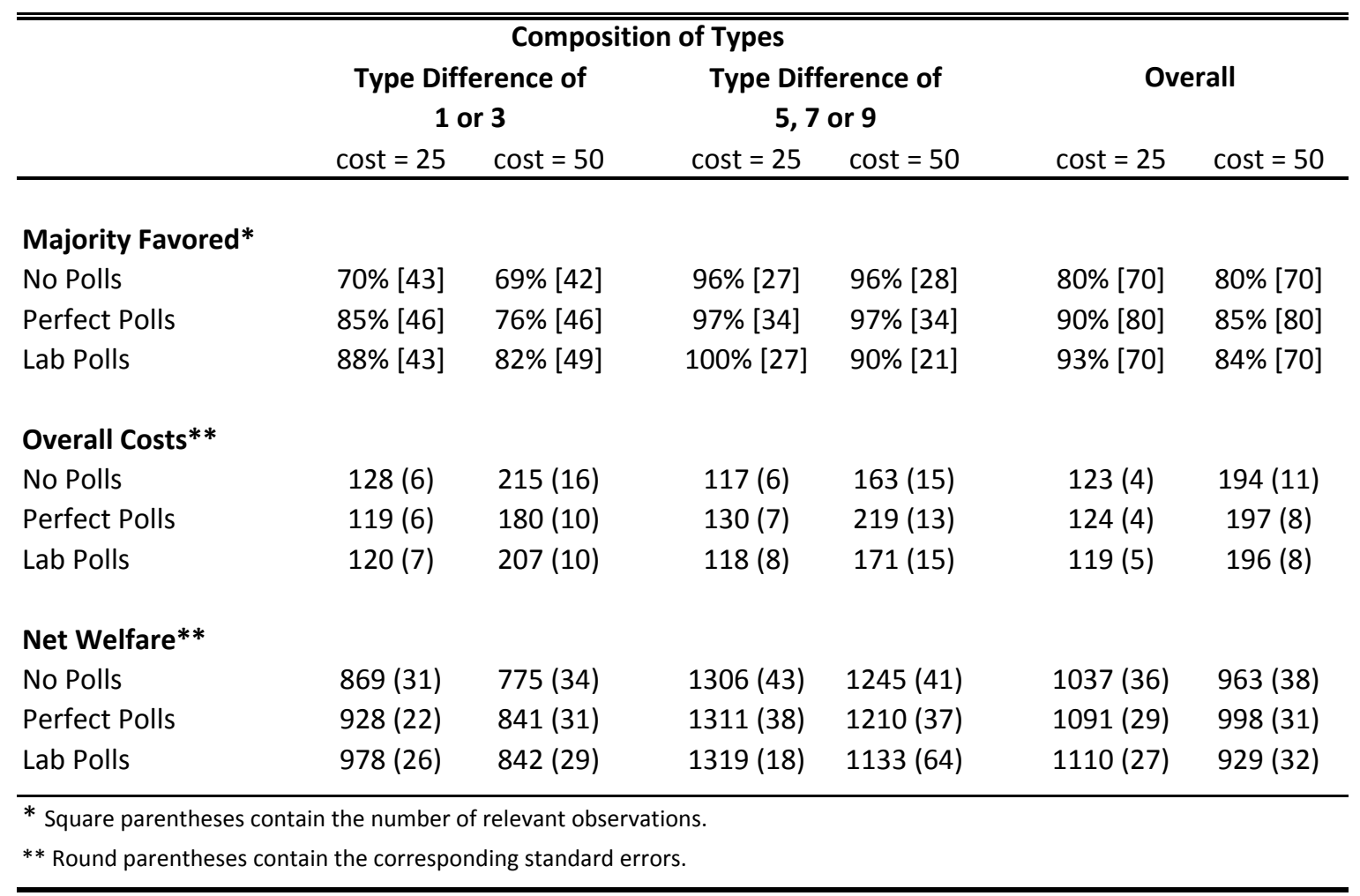

Table 5: Aggregate Election Outcomes

Though differences are not significant, we note that the welfare values observed do follow the theoretical comparative statics with respect to costs, generating greater mean observed welfare levels when participation costs are lower.

\section{Poll Reports}

Our Lab Polls treatment allows us to gain insight into how individuals respond to polls. In principle, since we see that poll results affect behavior and outcomes, individuals could potentially gain by misreporting their intended actions in the polling phase.

First, pre-election polls consistently overestimate voter turnout: while $82 \%$ of subjects reported they will vote, less than $50 \%$ actually did vote. This result mirrors the trend documented in the empirical literature that estimates turnout based on self reports in the American National Election Study (see Holbrook and Krosnick, 2010 and references therein). 
On the individual level, of those reporting they will vote, $42 \%$ of subjects voted. Nonetheless, subjects rarely voted for an alternative different than the one they declared they would vote for: of the subjects intending to vote, only $6 \%$ cast a vote for an alternative different than the one they chose in the poll.

In terms of incentives, individuals reporting a vote for their preferred candidate earned, on average, $\$ 1.15$ per election, individuals reporting a vote for their less preferred candidate earned an average of $\$ 0.98$, while individuals reporting abstention earned an average of $\$ 1.13$ (with standard errors of 3 cents, 10 cents, and 7 cents, respectively). That is, experimental incentives were such that reporting the genuinely preferred candidate or intended abstention generated greater payoffs. ${ }^{48}$ This is interesting in view of the theoretical predictions pertaining to the Lab Polls treatment. Indeed, subjects in our experiments did not follow the babbling equilibrium. Furthermore, a substantial fraction did not best respond at the polling stage. Nonetheless, a simple behavioral heuristic is consistent with some of our data. Suppose each subject assumes that all others follow their intended actions as declared in the poll. A subject would then vote only when pivotal according to the poll. Given our experimental poll results, such behavior would lead to a participation rate of $57 \%$, which is fairly close to what we observe.

Overall, polls reflect the ultimate election outcomes. Of the elections that did not end up in a tie, $84 \%$ of the outcomes coincided with those predicted by the polls.

In terms of outcomes, the literature on the effects of polls has identified two effects. The Bandwagon Effect suggests that the predicted winner in a poll gains additional support after the poll's publication. The Underdog Effect suggests that the predicted loser gains additional support after the poll's publication. Indeed, Bandwagon and Underdog Effects have been extensively studied in the recent few decades starting with the pioneering work of Simon (1954), Fleitas (1971), and Gartner (1976), among others (see Callander, 2007 and references therein for recent theoretical work on these phenomena). While most work is in consensus regarding the existence of these two effects, the debate about their magnitudes still goes on. Irwin and Van Holsteyn (2000) conduct a meta-study of the

\footnotetext{
${ }^{48}$ Note that since subjects respond to the magnitude of the lead in the polls, individuals are 'pivotal' for any profile of others' reports in the poll.
} 
empirical research on the two effects. The authors conclude that starting from the 1980s, a Bandwagon Effect was more frequent than an Underdog Effect.

Figure 4 depicts the realized lead as a function of the lead predicted by the polls. As can be seen, for moderate predicted leads, realized leads surpass those suggested by the poll, thereby confirming to a Bandwagon Effect. Nonetheless, when predicted leads are extreme (greater than 3), realized leads are more conservative, supporting an Underdog Effect. In other words, both effects gain support in our data, but which one prevails depends on whether or not the poll ends up in a close or landslide outcome. Furthermore, the magnitude of the effects depends on the precise poll outcomes. In particular, the underdog effect appears more pronounced as poll leads become substantial.

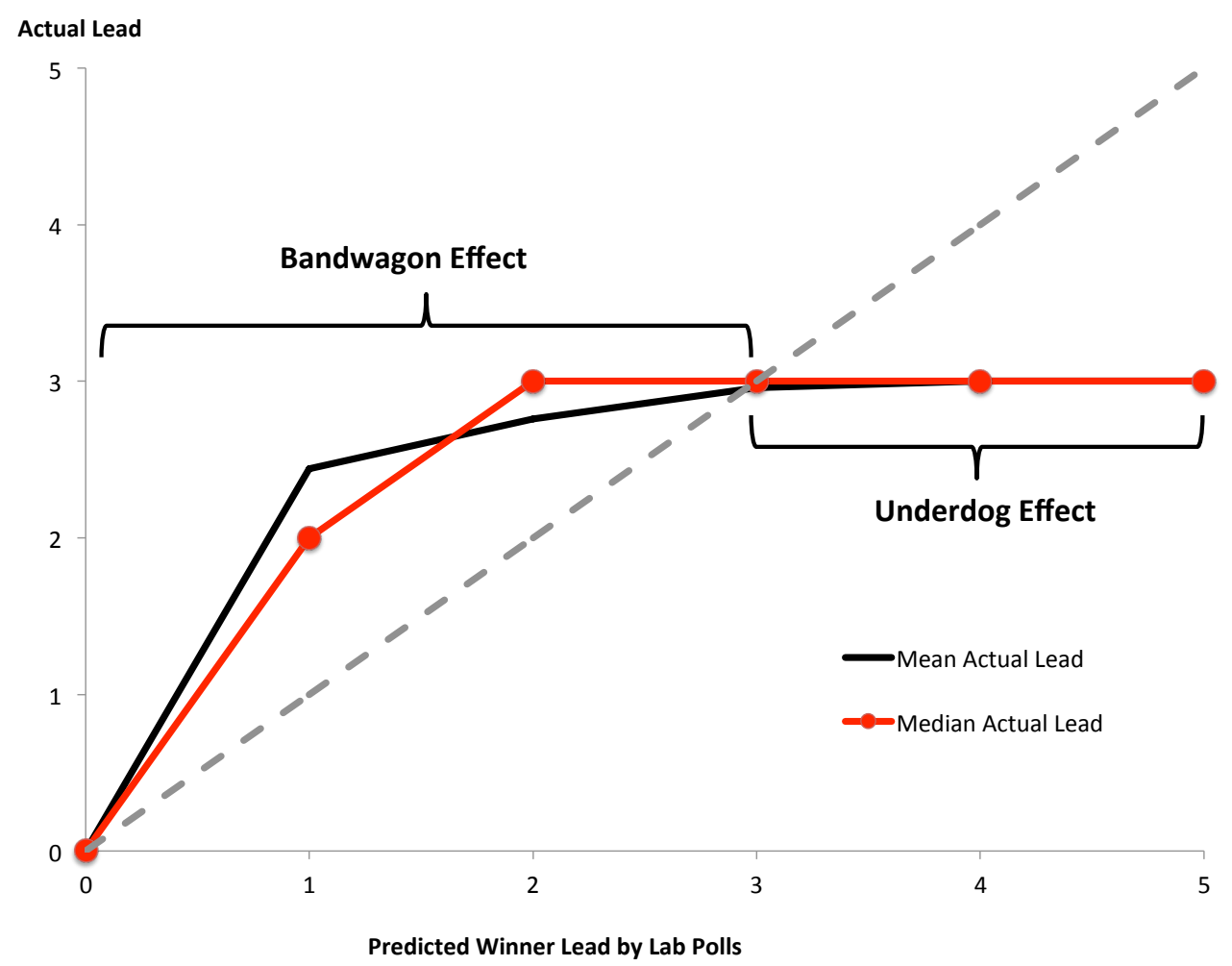

Figure 4: Bandwagon and Underdog Effects

One potential explanation for these observations is the following. Low poll leads are more likely to arise when there are relatively many individuals reporting abstention at the 
polling stage. In our data, $50 \%$ of those intending to abstain ultimately participated. Since participation is more likely when one's preferred alternative is leading in the polls, those reporting abstention at the polls serve to magnify the lead observed at the polling stage. Consequently, the difference between the actual lead and the poll lead of the winner is expected to increase with the number of those abstaining at the polls, consistent with the Bandwagon Effect we observe for low poll leads. For high poll leads, recall that $6 \%$ of our subjects voted for an alternative different than the one they chose in the poll. As it turns out, most of these subjects belonged to the minority group, and therefore contributed to an exaggerated poll lead. When poll leads are high, fewer individuals abstain and this pattern of behavior has more impact. This generates the observed Underdog Effect.

\section{Conclusions}

We provide an array of experiments that closely inspect voters' turnout response to beliefs regarding ultimate outcomes and the consequent effects of information about the electorate's underlying preferences, specifically in the form of polls. The first message that emerges from our analysis is that, contrary to the underlying premise of the pivotal voter model, the propensity to vote increases with subjects' predictions of their preferred alternative's advantage. This is the case despite our setting being, in many ways, conducive for the strategic considerations posited by the pivotal voter model to play out: our experimental groups are arguably small so that pivot probabilities are substantial and many external motives that may be important in large political elections (peer pressure to vote, changing knowledge about candidates, etc.) are controlled for. The monotonic response to beliefs about one's preferred alternative's likelihood of winning leads to the second message of the paper: pre-election polls do not exhibit the detrimental effects on welfare that the extant theoretical work on the effects of polls predicts. In fact, preelection polls lead to more participation by the expected majority and generate more landslide elections. Finally, our study provides insights on the behavior of individuals in polls and the responses they generate. We find that individuals report participation intentions that exceed the ultimate participation rates, but rarely misreport which can- 
didate they would support if intending to vote. This feeds into the impact of polls on outcomes. Close elections are more prone to Bandwagon Effects, by which poll winners gain even greater leads in the actual election, while landslide elections are more prone to Underdog Effects, where poll winners gain lower leads in the actual election.

The analysis suggests the usefulness of considering alternative theoretical constructs to that suggested by the canonical pivotal voter model. For instance, incorporating a desire to vote for winners, as suggested in Callander (2007), could generate predictions in line with our results and help explain much of the individual data observed in our experiments. In that respect, the paper opens the door to further experimentation targeted at isolating the precise voting motives collective action imposes. ${ }^{49}$

Last, our analysis raises questions regarding the value of polls. In our experiments, when observing the ex-ante majority-preferred alternative (namely, the color of the realized jar), the probability of that alternative being elected is $74 \%$ when no polls are available, $91 \%$ when perfect polls are available, and $83 \%$ when endogenous polls are utilized. This suggests the potential value of polls to well-informed candidates.

\footnotetext{
${ }^{49}$ For instance, it would be interesting to disentangle motives to vote with the winner from motives to vote with the majority (as in Goeree and Yariv, 2014), which the current design is not tailored for. A setting in which a minority selects the winner might be useful in teasing these motives apart.
} 


\section{References}

[1] Austen-Smith, D. and Banks, J. (1996), "Information Aggregation, Rationality, and The Condorcet Jury Theorem," American Political Science Review, Volume 90(1), pages 34-45.

[2] Borgers, T. (2004), "Costly Voting," American Economic Review, Volume 94, pages 57-66.

[3] Callander, S. (2007), "Bandwagons and Momentum in Sequential Voting," Review of Economic Studies, Volume 74, pages 653-684.

[4] Callander, S. (2008), "Majority Rule When Voters Like to Win," Games and Economic Behavior, Volume 64, pages 393-420.

[5] Cason, T. and Mui, V. (2005), "Uncertainty and resistance to reform in laboratory participation games," European Journal of Political Economy, Volume 21(3), pages 708-737.

[6] Coate, S. and Conlin, M. (2004), "A Group Rule-Utilitarian Approach to Voter Turnout: Theory and Evidence ," American Economic Review, Volume 94(5), pages 1476-1504.

[7] Coate, S., Conlin, M., and Moro, A. (2008), "The Performance of the Pivotal-Voter Model in Small-scale elections: Evidence from Texas Liquor Referenda," Journal of Public Economics, Volume 92(4), pages 582-96.

[8] Coughlan, P. (2000), "In Defense of Unanimous Jury Verdicts: Mistrials, Communication, and Strategic Voting," American Political Science Review, Volume 94(2), pages $375-393$.

[9] Duffy, J. and Tavits, M. (2008), "Beliefs and Voting Decisions: A Test of the Pivotal Voter Model," American Journal of Political Science, Volume 52(3), pages 603-618. 
[10] Feddersen, T. J., Gailmard, S., and Sandroni, A. (2009), "Moral Bias in Large Elections: Theory and Experimental Evidence," American Political Science Review, Volume 103(2), pages 175-192.

[11] Feddersen, T. J. and Pesendorfer, W. (1996), "The Swing Voter's Curse," American Economic Review, Volume 86(3), pages 408-424.

[12] Feddersen, T. J. and Pesendorfer, W. (1997), "Voting Behavior and Information Aggregation in Elections with Private Information," Econometrica, Volume 65(5), pages 1029-1058.

[13] Feddersen, T. J. and Pesendorfer, W. (1998), "Convicting the Innocent: The Inferiority of Unanimous Jury Verdicts under Strategic Voting," American Political Science Review, Volume 92(1), pages 23-35.

[14] Ferejohn, J. A. and Fiorina, M. P. (1974), "The Paradox of Not Voting: A Decision Theoretic Analysis," The American Political Science Review, Volume 68(2), pages 525-536.

[15] Fleitas, D. W. (1971), "Bandwagon and Underdog Effects in Minimal-Information Elections." American Political Science Review, Volume 65(2), pages 434-438.

[16] Forsythe, R., Myerson, R. B., Rietz, T. A., and Weber, R. J. (1993), "An experiment on coordination in multi-candidate elections: The importance of polls and election histories," Social Choice and Welfare, 10, pages 223-247.

[17] Fudenberg, D. and Levine, D. K. (1998), The Theory of Learning in Games, MIT Press.

[18] Galen, I. A. and Van Holsteyn, J. J. M. (2000), "Bandwagons, Underdogs, the Titanic, and the Red Cross: The Influence of Public Opinion Polls on Voters," Presented at the 18th World Congress of the International Political Science Association, Quebec, Canada. 
[19] Gartner, M. (1976), "Endogenous Bandwagon and Underdog Effects in a Rational Choice Model," Public Choice, Volume 25(1), pages 83-89.

[20] Gerardi, D. and Yariv, L. (2007), "Deliberative Voting," Journal of Economic Theory, Volume 134, pages 317-338.

[21] Goeree, J. K. and Großer, J. (2007), "Welfare Reducing Polls," Economic Theory, Volume 31(1), pages 51-68.

[22] Goeree, J. K. and Yariv, L. (2011), "An Experimental Study of Collective Deliberation," Econometrica, Volume 79(3), pages 893-921.

[23] Goeree, J. K. and Yariv, L. (2014), "Conformity in the Lab," forthcoming at The Journal of the Economic Science Association.

[24] Gneiting, T., and Raftery, A. E. (2007), "Strictly Proper Scoring Rules, Prediction, and Estimation," Journal of the American Statistical Association, Volume 102(477), pages 359-378.

[25] Großer, J. and Schram, A. (2010), "Public Opinion Polls, Voter Turnout, and Welfare: An Experimental Study," American Journal of Political Science, Volume 54 (3), pages $700-717$.

[26] Guarnaschelli, S., McKelvey, R. C., and Palfrey, T. R. (2000), "An Experimental Study of Jury Decision Rules," American Political Science Review, Volume 94(2), pages $407-423$.

[27] Hinich (1981), "Voting as an Act of Contribution," Public Choice, Volume 36(1), pages $135-140$.

[28] Holbrook, A. L. and Krosnick, J. A. (2010), "Social desirability bias in voter turnout reports: Tests using the item count technique," Public Opinion Quarterly, Volume 74 , pages $37-67$. 
[29] Kartal, M. (2014), "Laboratory Elections with Endogenous Turnout: Proportional Representation versus Majoritarian Rule," Experimental Economics, 10.1007/s10683014-9408-x.

[30] Klor, E. and E. Winter (2007), "The Welfare Effects of Public Opinion Polls," International Journal of Game Theory, Volume 35(3), pages 1270-1432.

[31] Levine, D. K. and Palfrey, T. R. (2007), "The Paradox of Voter Participation: A Laboratory. Study," American Political Science Review, Volume 101, pages 143-158.

[32] Morgan, J. and Stocken, P. C. (2008), "Information Aggregation in Polls," American Economic Review, Volume 98(3), pages 864-896.

[33] Mulligan, C. B. and Hunter, C. G. (2003), "The Empirical Frequency of a Pivotal Vote," Public Choice, Volume 116, pages 31-54.

[34] Myerson, R. (1998), "Extended Poisson Games and the Condorcet Jury Theorem," Games and Economic Behavior, Volume 25, pages 111-131.

[35] Ortoleva, P. and Snowberg, E. (2014), "Confidence and Overconfidence in Political Economy," forthcoming at American Economic Review.

[36] Palfrey, T. (2006), "Laboratory Experiments in Political Economy," in Weingast, B. and Wittman, D. (eds), Handbook of Political Economy, Oxford University Press: Oxford.

[37] Palfrey T. R. and Rosenthal, H. (1983), "A strategic calculus of voting," Public Choice, Volume 41(1), pages 7-53.

[38] Simon, H. A. (1954), "Bandwagon and Underdog Effects and the Possibility of Elections Predictions," Public Opinion Quarterly, Volume 18(3), pages 245-253.

[39] Sinclair, B. and Plott, C. (2012), "From Uninformed to Informed Choices: Voters, Pre-Election Polls and Updating," Electoral Studies, Volume 31(1), pages 83-95.

[40] Taylor C. R. and Yildirim, H. (2010), "Public Information and Electoral Bias," Games and Economic Behavior, Volume 68, 353-375. 